The INL is a

U.S. Department of Energy

National Laboratory

operated by

Battelle Energy Alliance

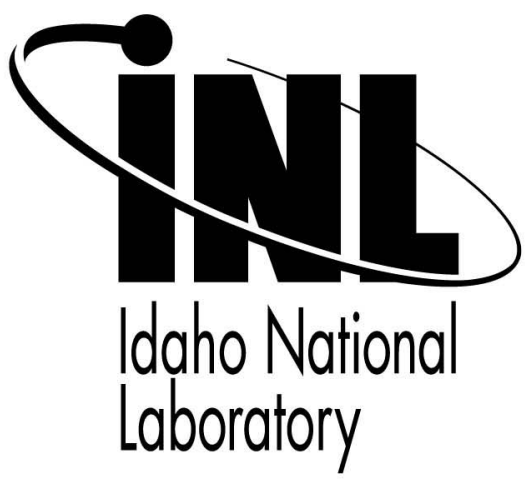

INL/CON-05-00270

PREPRINT

\section{Inert Matrix Fuel}

Neutronic, Thermal-

Hydraulic, and Transient

Behavior in a Light Water

Reactor

\section{European Materials Research Society Symposium N - Nuclear Materials}

\author{
W.J. Carmack \\ M. Todosow \\ M.K. Meyer \\ K.O. Pasamehmetoglu
}

May 2005

This is a preprint of a paper intended for publication in a journal or proceedings. Since changes may be made before publication, this preprint should not be cited or reproduced without permission of the author. This document was prepared as an account of work sponsored by an agency of the United States Government. Neither the United States Government nor any agency thereof, or any of their employees, makes any warranty, expressed or implied, or assumes any legal liability or responsibility for any third party's use, or the results of such use, of any information, apparatus, product or process disclosed in this report, or represents that its use by such third party would not infringe privately owned rights. The views expressed in this paper are not necessarily those of the United States Government or the sponsoring agency. 


\title{
Inert matrix fuel neutronic, thermal-hydraulic, and transient behavior in a light water reactor
}

\author{
W.J. Carmack ${ }^{\text {a,* }}$, M. Todosow ${ }^{\text {b }}$, M.K. Meyer ${ }^{\text {a }}$, K.O. Pasamehmetoglu ${ }^{\text {a }}$ \\ a Idaho National Laboratory, P.O. Box 1625, Idaho Falls, ID 83415-3860, USA \\ brookhaven National Laboratory, Brookhaven, NY, USA
}

\begin{abstract}
Currently, commercial power reactors in the United States operate on a once-through or open cycle, with the spent nuclear fuel eventually destined for long-term storage in a geologic repository. Since the fissile and transuranic (TRU) elements in the spent nuclear fuel present a proliferation risk, limit the repository capacity, and are the major contributors to the long-term toxicity and dose from the repository, methods and systems are needed to reduce the amount of TRU that will eventually require long-term storage. An option to achieve a reduction in the amount, and modify the isotopic composition of TRU requiring geological disposal is 'burning' the TRU in commercial light water reactors (LWRs) and/or fast reactors. Fuel forms under consideration for TRU destruction in light water reactors (LWRs) include mixed-oxide (MOX), advanced mixed-oxide, and inert matrix fuels. Fertile-free inert matrix fuel (IMF) has been proposed for use in many forms and studied by several researchers. IMF offers several advantages relative to MOX, principally it provides a means for reducing the TRU in the fuel cycle by burning the fissile isotopes and transmuting the minor actinides while producing no new TRU elements from fertile isotopes. This paper will present and discuss the results of a four-bundle, neutronic, thermal-hydraulic, and transient analyses of proposed inert matrix materials in comparison with the results of similar analyses for reference UOX fuel bundles. The results of this work are to be used for screening purposes to identify the general feasibility of utilizing specific inert matrix fuel compositions in existing and future light water reactors. Compositions identified as feasible using the results of these analyses still require further detailed neutronic, thermal-hydraulic, and transient analysis study coupled with rigorous experimental testing and qualification.
\end{abstract} c.

\footnotetext{
* Corresponding author. Tel.: +1 208 526 6360; fax: +1 208526 2930

E-mail addresses: jon.carmack@inl.gov, wjc@inel.gov (W.J. Carmack).
}

\section{Introduction}

The Advanced Fuel Cycle Initiative Light Water Reactor transmutation fuel development program plans to test both mixed-oxide (MOX) and inert matrix fuel (IMF) in an irradiation test, designated LWR-2, in the Advanced Test Reactor, located at 
the Idaho National Laboratory. The goal of the AFCI LWR transmutation program is to develop a fuel composition that fulfills four general criteria:

1. The fuel must produce the same power as a standard uranium oxide (UOX) fuel in a light water reactor.

2. The fuel composition must target destruction of actinide species ( $\mathrm{Pu}, \mathrm{Am}$, and $\mathrm{Np}$ ) and emphasize proliferation resistant forms.

3. The fuel must perform these functions without greatly increasing the fissile material loading (which affects fuel cycle cost) in the overall nuclear fuel cycle, and should be within the existing safety envelope of commercial LWRs.

4. The fuel composition must allow for extraction and processing to recover the heavy metal for possible further destruction (via recycling into LWRs or fast reactors) or treatment for ultimate burial in a geologic repository.

To provide for flexibility in the incorporation of plutonium/actinide bearing fuels in pressurized and boiling water reactors, a variety of MOX and IMF compositions are being proposed for inclusion in the planned AFCI irradiation experiment, LWR-2. A variety of compositions are needed to determine the feasibility and performance of fuels containing significant amounts of TRU, and allow for flexibility in loading strategies for fuel management. This paper will explore the general neutronic and thermalhydraulic performance of transmutation fuels based on the fertile-free matrix material magnesia-zirconia $\left(\mathrm{MgO}-\mathrm{ZrO}_{2}\right)$. For comparison the neutronic and thermal-hydraulic performance characteristics of uranium dioxide (UOX), yttria-stabilized zirconia (YSZ) and SiC fuels are presented.

A variety of inert matrix materials compositions have been proposed and studied for use in high burnup actinide fuel systems, Degueldre and Yamashita [1]. Chang and Ryskamp [2] proposed inert matrix fuel pins inter-dispersed in standard LWR $\mathrm{UO}_{2}$ fuel bundles to achieve burnup and destruction of $\mathrm{Pu}$ material without negatively impacting operational characteristics of LWR operation. Herring et al. [3] proposed a $\mathrm{ThO}_{2}$ based transmutation fuel for LWR systems to eliminate the ${ }^{238} \mathrm{U}$ matrix from the reactor system entirely. Eaton et al. [4] proposed a full inert matrix of $\mathrm{ZrO}_{2}$ stabilized with $\mathrm{CaO}$ and loaded with TRU. Much work has been performed in the yttria-stabilized zirconia (YSZ) matrix system for application to once-through and out (OTTO) fuel cycles, Schram et al. [5], Ledergerber et al. [6]. Irradiation and property test programs performed on the YSZ matrix have indicated excellent stability and performance both as a fuel system and as a final waste form meeting repository waste disposal criteria. In a once through fuel application Hellwig et al. [7] irradiated a YSZ matrix. The study compositions attained $440 \mathrm{kWd} \mathrm{cm}^{-3}$ burnup with no measurable fission gas release. The composition densified to $100 \%$ TD and pellet center-line temperature was found to be approximately $300-400 \mathrm{~K}$ higher than a comparable MOX fuel center-line temperature.

To implement an inert matrix fuel composition in the US commercial LWR fleet, the matrix composition must be insoluble in water, and should have a thermal conductivity higher than that found in the cubic $\mathrm{ZrO}_{2}$. Preliminary property tests and fabrication trials by Medvedev $[8,9]$ at the Idaho National Laboratory have indicated that the performance of a dual phase $\mathrm{MgO}-\mathrm{ZrO}_{2}$ matrix may be able to meet the requirements of the AFCI LWR fuel program. The AFCI LWR fuel development program intends to fabricate and test a variety of fuel $\mathrm{MgO}-\mathrm{ZrO}_{2} \mathrm{com}$ positions in an irradiation campaign in the Advanced Test Reactor located at the Idaho National Laboratory in late-2006. The test will contain both IMF compositions and MOX fuel compositions for comparison. Some of the tested compositions will also include americium and neptunium to investigate the effect of minor actinides on the fuel matrices.

Fuel compositions actually employed in LWR transmutation fuels will be significantly affected by what TRU streams can be easily extracted in the separations process. The 'conventional' streams are $\mathrm{Pu}$ (which might not be allowed from proliferation concerns), $\mathrm{Np}+\mathrm{Pu}$ (which is considered to have enhanced proliferation resistance; this fuel will result in some Am being present from the decay of ${ }^{241} \mathrm{Pu}$ after separation through fabrication and prior to reactor insertion), and $\mathrm{Np}+\mathrm{Pu}+\mathrm{Am}$. Current plans do not envision the inclusion of curium. Table 1 presents a summary of the currently planned fuel compositions in the LWR-2 test series.

The $\mathrm{MgO}-\mathrm{ZrO}_{2}$ dual phase ceramic provides a combination of the properties of $\mathrm{MgO}$ and of $\mathrm{ZrO}_{2}$ that may be able to fulfill the goals of the US LWR transmutation fuel program. When combined in the dual phase ceramic, the high thermal conductivity of $\mathrm{MgO}$ tends to overcome the poor thermal conductivity of $\mathrm{ZrO}_{2}$, Medvedev [9]. The addition of $\mathrm{MgO}$ to $\mathrm{ZrO}_{2}$ in significant quantity 
Table 1

Proposed MOX and $\mathrm{MgO}-\mathrm{ZrO}_{2}$ compositions to be included in the LWR-2 irradiation test

\begin{tabular}{|c|c|c|}
\hline & Description & Composition \\
\hline 2 pins & MOX composition at high burnup & $\mathrm{PuO}_{2}-\mathrm{UO}_{2}$ \\
\hline 2 pins & IMF replacement to MOX matrix & $\mathrm{PuO}_{2}-\mathrm{MgO}-\mathrm{ZrO}_{2}$ \\
\hline 2 pins & IMF replacement to MOX matrix, Np addition ${ }^{2}$ & $(\mathrm{Pu}, \mathrm{Np}) \mathrm{O}_{2}, \mathrm{MgO}-\mathrm{ZrO}_{2}$ \\
\hline 2 pins & MOX, Np, Am additions & $(\mathrm{Am}, \mathrm{Pu}, \mathrm{Np}) \mathrm{O}_{2}-\mathrm{UO}_{2}$ \\
\hline 2 pins & IMF replacement to $\mathrm{MOX}, \mathrm{Np}, \mathrm{Am}$ additions ${ }^{\text {il }}$ & $(\mathrm{Am}, \mathrm{Pu}, \mathrm{Np}) \mathrm{O}_{2}, \mathrm{MgO}-\mathrm{ZrO}_{2}$ \\
\hline
\end{tabular}

a The fissile phase of the inert matrix compositions is envisioned to be separate from the dual phase $\mathrm{MgO}_{-} \mathrm{ZrO}_{2}$ phase, although it is know that $(\mathrm{Pu}, \mathrm{Am}, \mathrm{Np}) \mathrm{O}_{2}$ will tend to dissolve in the $\mathrm{ZrO}_{2}$ phase.

has been found to increase the thermal conductivity of the matrix material greater than standard UOX or MOX fuel compositions. The stability of $\mathrm{ZrO}_{2}$ in water tends to overcome the dissolution of $\mathrm{MgO}$ in water. Having the ability to balance the thermal conductivity of the fuel with the capability for dissolution makes the $\mathrm{MgO}-\mathrm{ZrO}_{2}$ ceramic a leading candidate for an inert matrix material. $\mathrm{MgO}$ and $\mathrm{ZrO}_{2}$ both are known to have acceptable irradiation performance and demonstrating the performance of a $\mathrm{Pu}$-bearing $\mathrm{MgO}-\mathrm{ZrO}_{2}$ fuel composition with additions of $\mathrm{AmO}_{2}$ and $\mathrm{NpO}_{2}$ will facilitate selection of this composition for further development as a transmutation fuel for LWRs.

Due to the fission efficiency of reactor-grade plutonium the use of burnable poisons will likely be required to control excess reactivity throughout the fuel life, control the power distribution within an acceptable range, and provide additional Doppler feedback in inert matrix fuel compositions. Erbium oxide may be added to the inert matrix fuel compositions to achieve these objectives. Porta and Asou [10], recommend less than $3 \mathrm{wt} \%$ additions of erbia to the fuel matrix since additions of erbia tend to decrease thermal conductivity. Medvedev [9] measured a depression in thermal conductivity of $\mathrm{MgO}-\mathrm{ZrO}_{2}$ with erbia additions and therefore these additions must be balanced.

To study these issues, a neutronic/thermalhydraulic/transient screening analysis is conducted. The following sections present the analysis methodology and the results as applied to inert matrix compositions of interest with emphasis on the $\mathrm{MgO}-\mathrm{ZrO}_{2}$ system.

\section{Analysis}

To screen candidate inert matrix fuel compositions for potential use in LWRs an integrated methodology is used which considers neutronic, thermal-hydraulic, and transient/accident aspects. This paper presents the results of this screening analysis performed on one of the above inert matrix compositions $\left(\mathrm{Am}_{x}\right.$, $\left.\mathrm{Pu}_{x}, \mathrm{~Np}_{x}\right) \mathrm{O}_{2}-\mathrm{MgO}-\mathrm{ZrO}_{2}$, and compares the results to an analysis performed in a previous study by Todosow et al. [11] which considered the same fuel with UOX, $\mathrm{ZrO}_{2}$, and $\mathrm{SiC}$ matrix materials.

The reference core for this analysis is a typical 4-loop Westinghouse PWR with a thermal power of $3400 \mathrm{MW}$ and $19317 \times 17$ fuel assemblies. The reference fuel is low enriched $(<5 \mathrm{wt} \%){ }^{235} \mathrm{U}$, uranium oxide capable of achieving an 18-month cycle, and a typical fuel management strategy with 3batches, and once through then out with geological repository storage for the discharged spent nuclear fuel. Neutronic calculations are limited to an infinite array of fuel assemblies, and 'colorset' geometries that model the four neighboring quadrants of four neighboring assemblies. Fig. 1 is a colorset geometry representing 3-UOX assemblies and 1-IMF assembly. Note that the IMF assembly (upper-right) assumes an annular fuel rod with a central plug to compensate for the possible lower thermal conductivity of the inert matrix. While this is true for a pure $\mathrm{ZrO}_{2}$ matrix, it may not be necessary with other matrix materials as discussed earlier. The IMF fuel in all cases is assumed to contain $\mathrm{Np}$, $\mathrm{Pu}$, and $\mathrm{Am}$ in oxide form, with an isotopic distribution characteristic of the discharge fuel from an advanced LWR with a burnup of $51 \mathrm{MWd} \mathrm{kg}^{-1}$, after 5-years of cooling and post-fabrication. The isotopic vector for 5-year cooled, recycled TRU is provided in Table 2; alternate vectors with curium separation performed at 10 and 20 years of cooling are also provided for reference. The neutronics calculations are supplemented by steady state thermalhydraulics, and selected system transient/accident analyses. Using the results of theses analyses, preliminary conclusions can be drawn regarding the viability of proposed IMF with respect to conventional (Pu-only) and modified (e.g., $\mathrm{Np}+\mathrm{Pu}$, $\mathrm{Np}+\mathrm{Pu}+\mathrm{Am}$ ) MOX, and UOX fueled cores. 


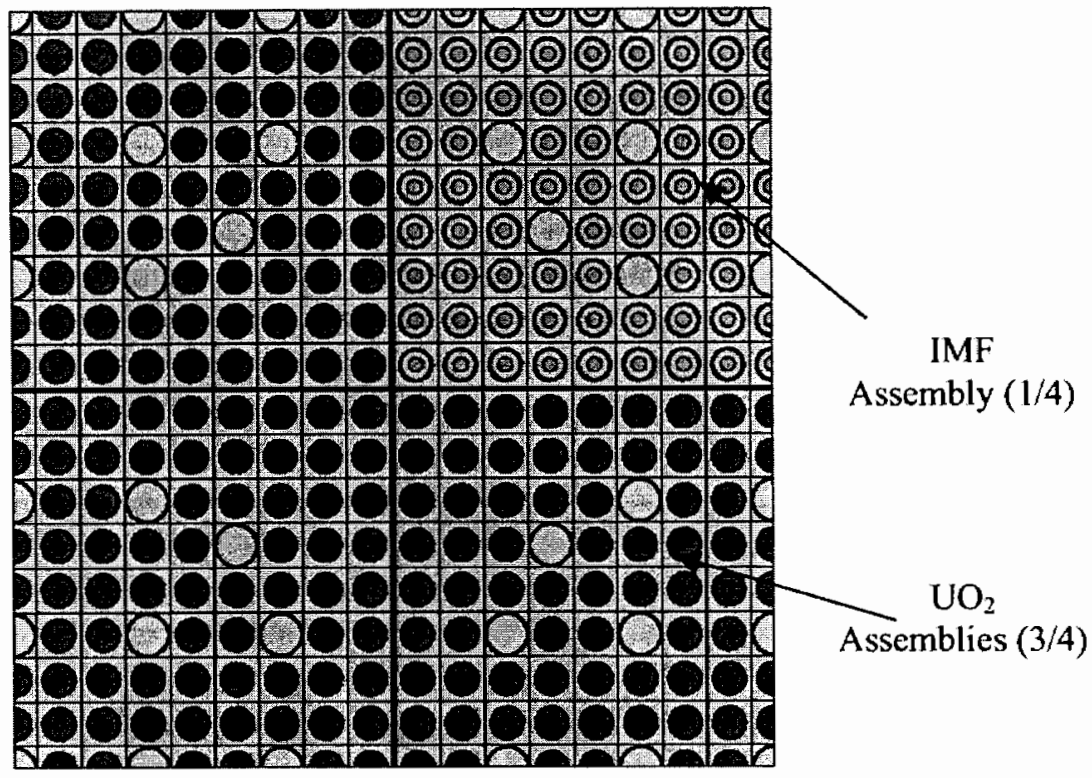

Fig. 1. MCNP colorset geometry for 1-IMF assembly and 3-UOX assemblies.

Table 2

Plutonium, neptunium, and americium isotopic vector (\%) in (51 $\mathrm{MWd} \mathrm{kg}^{-1}$ ) spent $\mathrm{UO}_{2}$

\begin{tabular}{lrrr}
\hline Cooling time (years) & \multicolumn{3}{c}{ Isotopic abundance (\%) } \\
\cline { 2 - 4 } & \multicolumn{1}{c}{5} & \multicolumn{1}{c}{10} & \multicolumn{1}{c}{20} \\
\hline Isotope & & & \\
${ }^{238} \mathrm{Pu}$ & 2.376 & 2.284 & 2.112 \\
${ }^{239} \mathrm{Pu}$ & 47.924 & 47.927 & 47.948 \\
${ }^{240} \mathrm{pu}$ & 22.674 & 22.759 & 22.890 \\
${ }^{241} \mathrm{Pu}$ & 10.669 & 8.390 & 5.190 \\
${ }^{242} \mathrm{pu}$ & 6.646 & 6.647 & 6.651 \\
${ }^{241} \mathrm{Am}$ & 3.400 & 5.682 & 8.892 \\
${ }^{242 \mathrm{~m}} \mathrm{Am}$ & 0.007 & 0.007 & 0.007 \\
${ }^{243} \mathrm{Am}$ & 1.518 & 1.518 & 1.519 \\
${ }^{237} \mathrm{~Np}$ & 4.786 & 4.786 & 4.790 \\
\hline
\end{tabular}

\subsection{Neutronic analysis}

The reactor physics calculations presented here were carried out with the BOXER lattice physics code [12] with nuclear data based on JEF1.1. The BOXER code and models have been extensively benchmarked against several standard nuclear design codes, with a variety of nuclear data libraries to qualify its use for these analyses. The analyses include evaluation of the moderator temperature coefficient (MTC), Doppler coefficient, soluble boron reactivity worth, coolant void coefficient, and control rod system (CR) reactivity worth, and reactivity vs. burnup. Rod-wise power distributions and kinetics parameters are also determined for use in the thermal-hydraulic and safety analyses. Kinetics parameters include: prompt neutron lifetime, delayed neutron fraction, and decay constants.

\subsection{Thermal analysis}

The thermal-hydraulic performance of a 3-UOX/ l-IMF 'colorset' assembly configuration was evaluated by using the COBRA-EN code [13]. Minimum departure from nucleate boiling ratio (MDNBR) is used as a figure of merit for the margin to thermal limits in the hottest or highest power region of the core. The thermal conductivity of the fuel matrix does not enter into this analysis due to the steady state nature of the heat transfer. The MDNBR generally depends on the temperature of the clad surface at steady state which is dependent upon the heat generation rate in the fuel.

\subsection{Transient/safety analysis}

Transient/safety analyses are performed using the RELAP5-3D systems computer code [14] modeling selected scenarios taking a 4-loop PWR plant as the model. Accidents that have been considered include: (1) a loss of coolant accident (LOCA) in the cold leg of the primary loop; (2) loss of primary flow; and (3) loss of power transients for a mixed core containing 3-UOX and 1-IMF assemblies in a 
'colorset'. Reactor kinetics was modeled by a point kinetics model with reactivity feedbacks from moderator void, moderator temperature, and fuel temperature (Doppler effect). A large-break loss of coolant accident (LBLOCA) was analyzed earlier. Three factors rise as key measures of inert matrix loaded core transient behavior; hot pin radial peaking, thermal conductivity, and fuel volumetric heat capacity. A fuel matrix with low thermal conductivity will end up having a higher peak clad temperature during transients (loss of cooling, etc.) due to its inability to transfer heat effectively to the cladcoolant boundary. This causes a higher rise in fuel temperature during the accident progression. Temperature rises higher than that experienced in standard UOX fueled reactor cores may compromise the safety envelope and therefore inert matrix fuel development generally focuses on inert matrix material compositions having thermal conductivity equivalent to or higher than that of UOX matrix fuel. As noted earlier, annular fuel pellets may also be used to reduce the maximum fuel temperature. Other factors such as differences in the reactivity coefficients, kinetics parameters, and control worths will have an effect on the progression of the accident (e.g., power profile, effectiveness of scram, etc.).

\section{Results}

\subsection{Neutronic}

Results are shown in Fig. 2 for the burnup in full power day (FPd) vs. the $k_{\text {inf }}$ behavior for several matrix compositions of interest. Since the actinide loading for all IMF cases is the same, the results show that the impact of different matrix materials on the cycle length is slight.

In addition to the achievable cycle length, typical reactivity, and control coefficients were also evaluated and are shown in Table 3. The presence of $\mathrm{Pu}$ and other TRU isotopes is known to 'degrade' some of these parameters relative to a conventional UOX fueled system. In particular, the worth of soluble boron and control rods decreases with increasing loading of $\mathrm{Pu}$ and other TRU, and at sufficiently high loadings, the void coefficient becomes positive. Also shown are results for an IMF assembly with reactor-grade $(R G)$ plutonium that is based on that employed in a full-core PWR design proposed by the Paul Scherrer Institute (PSI), as well as representative values for a RG-Pu MOX assembly, and from the safety analysis report. The results show that, as expected, the most significant impact of IMF fuel is a reduction in the Doppler coefficient due to the absence of fertile material like ${ }^{238} \mathrm{U}$, and the soluble boron worth relative to conventional uranium oxide fuel; the MTC and void coefficients do not differ appreciably. The results for zirconium oxide and silicon carbide matrix materials are very similar. The IMF results with TRU for the MTC, the void coefficient, and the estimated control rod (Ag--In-Cd) are close to those obtained by PSI. The Doppler coefficient is less negative, while the soluble boron worth is more negative than for the PSI design. These results suggest a TRUIMF design similar to that considered here is feasible/viable for implementation in a LWR. The behavior for an $\mathrm{MgO}-\mathrm{ZrO}_{2}$ matrix is similar to the other IMF results. These results suggest that mixed cores of IMF and UOX assemblies are the most likely implementation approach in order to keep an existing LWR within its licensed safety envelope.

\subsection{Thermal-hydraulic}

Table 4 presents a summary of the primary heat transfer parameters for the $\mathrm{UO}_{2}, \mathrm{MgO}-\mathrm{ZrO}_{2}$, and $\mathrm{SiC}$. The thermal conductivity of the fuel matrix does not greatly affect the MDNBR analysis due to the steady state nature of the analyses. The MDNBR generally depends on the temperature of the clad surface at steady state which is dependent upon the heat generation rate found in the fuel. The heat generation rate depends on the fissile loading and the neutron density found in the reactor core. Hence, the matrix material generally only has an effect on the MDNBR as a result of changes in the power distribution. The analysis conducted for the purpose of this paper has found that the matrices of interest do not greatly affect the performance of the fuel when compared to a standard MOX composition. MOX is known however to generally operate from 200 to $300 \mathrm{~K}$ greater than a comparable UOX composition [6].

\subsection{Transient/safety}

As illustrated above the general neutronic and thermal-hydraulic performance of the candidate IMF compositions does not depend greatly on the thermal conductivity of the matrix. Thermal conductivity does however, play an important role in the transient behavior of the fuel and the thermal 


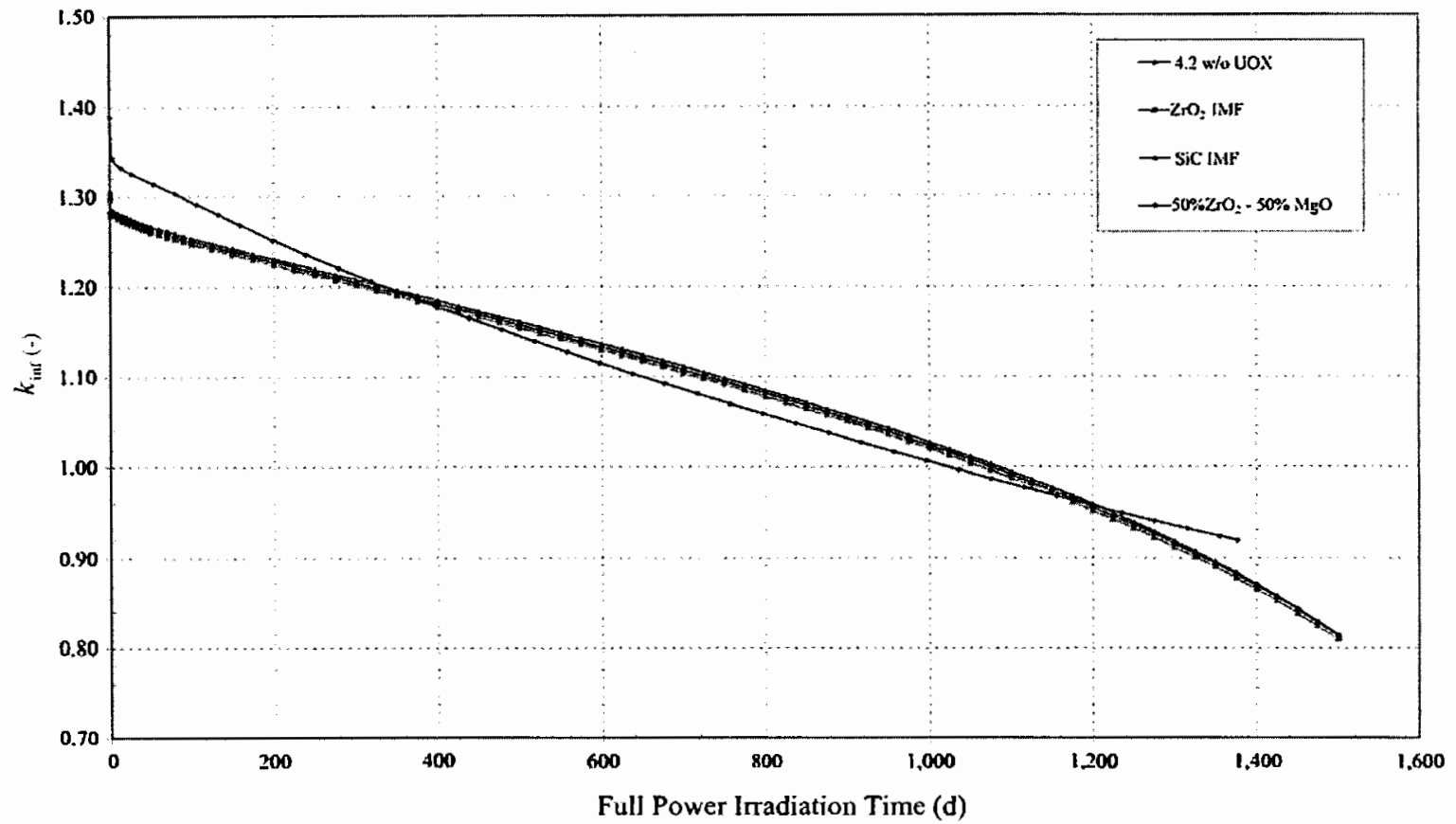

Fig. 2. $k_{\text {inf }}$ vs. full power day burnup graph comparison between $\mathrm{ZrO}_{2}, \mathrm{SiC}, \mathrm{MgO}-\mathrm{ZrO}_{2}$, and $\mathrm{UOX}$.

Table 3

Reactivity coefficients and control worths for westinghouse $17 \times 17$ assembly for standard uranium oxide and inert matrix fuels at beginning of life (BOL)

\begin{tabular}{|c|c|c|c|c|c|c|}
\hline \multirow[t]{2}{*}{ Reactivity coefficients } & \multirow[t]{2}{*}{$4.3 w t \%$ UOX } & \multicolumn{2}{|c|}{$\mathrm{Np}+\mathrm{Pu}+\mathrm{Am}$ from ALWR } & \multirow{2}{*}{$\begin{array}{l}\text { PSI IMF } \\
(\mathrm{RG}-\mathrm{Pu}-\mathrm{Zr}-\mathrm{Er}) \mathrm{O}_{2}\end{array}$} & \multirow{2}{*}{$\begin{array}{l}\text { MOX } \\
(7 \mathrm{wt} \% \text { of } \mathrm{Pu})\end{array}$} & \multirow{2}{*}{$\begin{array}{l}\text { Ref. safety } \\
\text { analysis report }\end{array}$} \\
\hline & & $(\mathrm{TRU}-\mathrm{Zr}) \mathrm{O}_{2}$ & $(\mathrm{TRU}) \mathrm{O}_{2}-\mathrm{SiC}$ & & & \\
\hline \multicolumn{7}{|l|}{ No soluble boron } \\
\hline Void (pcm $\left.(\%)^{-1}\right)$ & -139 & -106 & -109 & -105 & -105 & - \\
\hline $\operatorname{MTC}\left(\mathrm{pcm} \mathrm{K}^{-1}\right)^{\prime}$ & -37 & -33 & -33 & -35 & -41 & 0 to -72 \\
\hline Doppler $\left(\mathrm{pcm} \mathrm{K}^{-1}\right)$ & -2.5 & -1.3 & -1.4 & -1.8 & -2.9 & -5.2 to -2.5 \\
\hline Boron worth $\left(\mathrm{pcm} \mathrm{ppm}^{-1}\right)$ & -8 & -3.1 & -3.1 & -2.4 & -2 & -16 to -8 \\
\hline Estimated $61 \mathrm{CR}$ worth $(\% \Delta \rho)$ & -10 & -6 & -6 & -6 & - & $\begin{array}{l}-9.0(\mathrm{BOC}) \\
\text { to }-8.5(\mathrm{EOC})\end{array}$ \\
\hline \multicolumn{7}{|l|}{$500 \mathrm{ppm}$ of soluble boron } \\
\hline Void (pcm $\left.(\%)^{-1}\right)$ & -94 & -85 & -90 & -88 & - & - \\
\hline $\operatorname{MTC}\left(\mathrm{pcm} \mathrm{K}^{-1}\right)$ & -24 & -26 & -27 & -30 & - & - \\
\hline
\end{tabular}

EOL: end of life, BOL: beginning of life, BOC: beginning of cycle, EOC: end of cycle, MTC: moderator temperature coefficient.

Table 4

Fuel material thermal-hydraulic characteristics

\begin{tabular}{llll}
\hline Parameters & PWR $\left(\mathrm{UO}_{2}\right)$ & IMF $\left(\mathrm{ZrO}_{2} / \mathrm{MgO}\right)$ & $\mathrm{IMF}(\mathrm{SiC})$ \\
\hline Hot pin radial peaking ratio & $1.674(1.5678 \times 1.068)$ & $1.980(1.5678 \times 1.263)$ & $1.980(1.5678 \times 1.263)$ \\
Thermal conductivity, $\left(\mathrm{W} \mathrm{m}^{-1} \mathrm{~K}^{-1}\right)$ & $5.14($ at $616 \mathrm{~K})$ & $5(\text { constant })^{\mathrm{a}}$ & $25.12($ at $673 \mathrm{~K})$ \\
& $2.98($ at $1200 \mathrm{~K})$ & & $16.12($ at $1273 \mathrm{~K})$ \\
Volumetric heat capacity, $\left(\mathrm{J} \mathrm{m}^{-3} \mathrm{~K}^{-1}\right)$ & $3.14 \times 10^{6}($ at $673 \mathrm{~K})$ & $4.22 \times 10^{6}$ (constant) & $3.37 \times 10^{6}($ at $600 \mathrm{~K})$ \\
& $3.44 \times 10^{6}$ (at $\left.1373 \mathrm{~K}\right)$ & & $4.01 \times 10^{6}($ at $1200 \mathrm{~K})$ \\
\hline
\end{tabular}

a Value held constant for this analysis due to uncertainty in the currently available data. 
conductivities of the proposed compositions vary significantly. Thermal conductivity generally governs the rate at which decay heat is transferred to the clad/coolant boundary and hence affects the rate at which a reactor core cools or heats up during a transient scenario. The three accidents analyzed for this paper illustrate the potential impacts of introducing IMF into an LWR. Key results are discussed to demonstrate the influence of performance parameters on the progression and consequences of various accident scenarios.

To illustrate the behavior of the candidate IMF materials, Fig. 3 shows a comparison between peak clad temperature (PCT) for the hot pin for a UOX loaded core and the hot pin for the IMF materials in a mixed UOX/IMF core using materials, $\mathrm{ZrO}_{2}-$ $\mathrm{MgO}$ and $\mathrm{SiC}$ under a loss of coolant accident (LOCA).

In a mixed UOX/IMF core, the relative magnitude of the PCT in the IMF and the UOX hot assembly is a direct consequence of the core power distribution. In the RELAP5 model, the hottest fuel pin shares the same coolant channel with the rest of the fuel pins in the hottest fuel assembly. Thus the PCT is a function of both the pin power and the hot assembly power which determines the bulk coolant temperature experienced by the hot pin. According to the result of the 'colorset' calculation each UOX assembly generates more power than the surrounding IMF assembly. On the other hand the peak fuel pin in the 'colorset' is found in the IMF assembly. Thus the hottest fuel pin in the core is located separate from the hottest fuel assembly in the core. The RELAP5 results indicate that the maximum PCT in a LOCA occurs in the hottest
UOX assembly in a mixed core. Because of the lower power in the IMF assembly the PCT for IMF is lower than the corresponding PCT for the UOX assembly.

In comparing the PCT for the UOX fuel in a mixed core and the PCT for the UOX fuel in a standard PWR it is noted that the pin-wise power distribution is more uniform in the fuel assemblies of a standard PWR. This results in the $\mathrm{UO}_{2}$ fuel in a standard PWR having a lower PCT than that for the UOX assembly in a mixed core.

In addition to LOCA, two additional transients have been analyzed for the mixed UOX/IMF cores and a standard PWR UOX core. The two transients are loss of power and loss of primary flow. Fig. 4 shows the PCT behavior with time under loss of power and loss of primary flow scenarios. A loss of power transient assumes tripping of the primary pumps, the turbine and the main feedwater pumps, followed by a reactor trip. After $75 \mathrm{~s}$ from the reactor trip only the emergency feedwater pump is assumed to inject emergency feedwater to the four steam generators. The PCT in this transient experienced an initial decrease after the reactor trip followed by a slow increase due to a reduction in heat removal by the steam generators. The upward trend of the PCT was finally mitigated by the injection of emergency feedwater that restored the heat removal capacity of the steam generators.

A loss of primary flow transient was initiated by a trip of the primary pumps at time zero, followed by a reactor trip at $87 \%$ flow. There was about a $5 \mathrm{~s}$ delay in the reactor trip while the core flow is reduced due to the pump trip. With a decrease in core flow the core coolant temperature began to
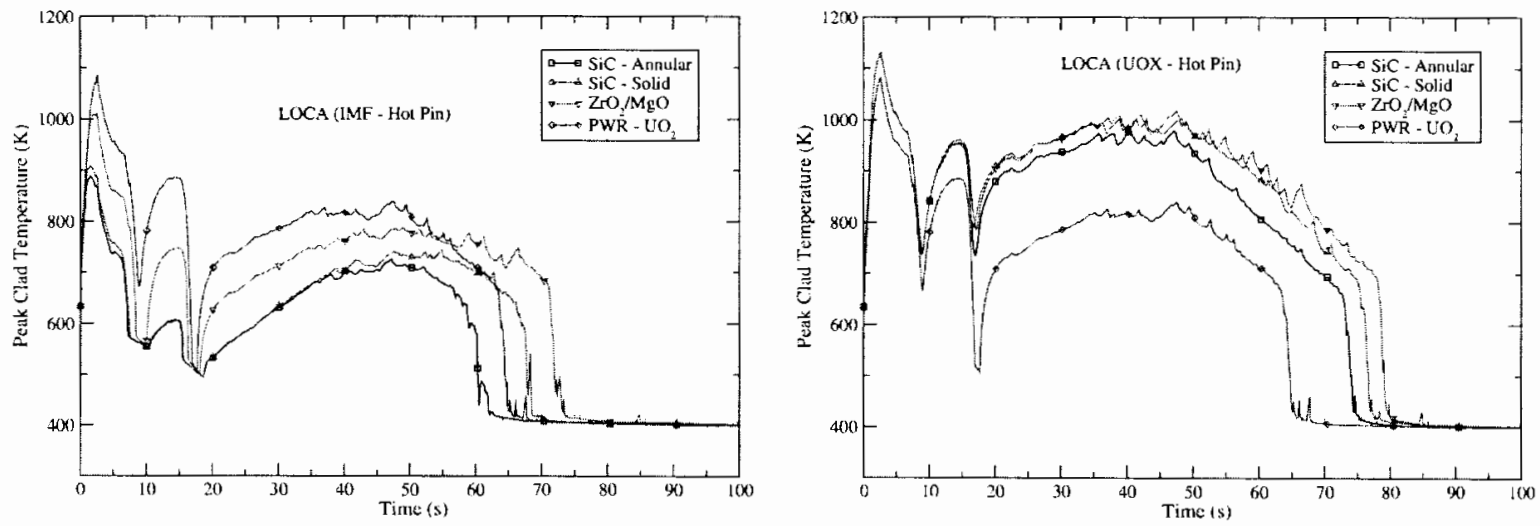

Fig. 3. Peak clad temperature for hot pin comparison between $\mathrm{MOX}$ and $\mathrm{ZrO}_{2}-\mathrm{MgO}$ and $\mathrm{SiC}$ inert matrix materials. 

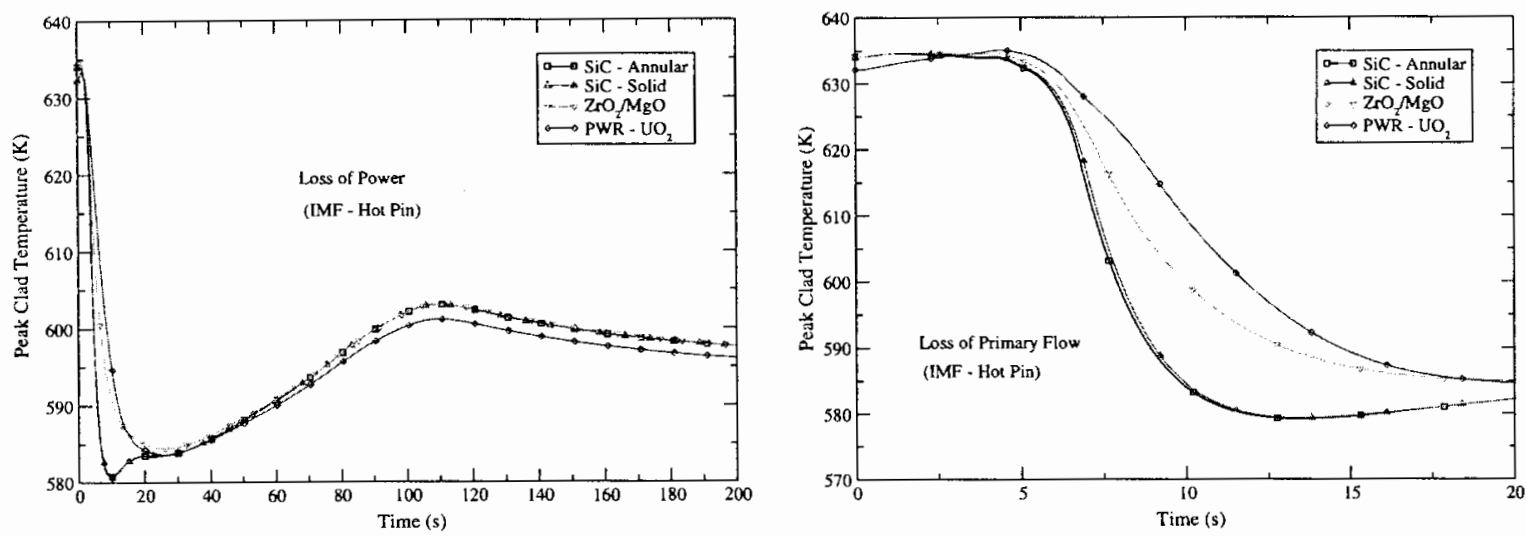

Fig. 4. Peak clad temperature for hot pin for loss of power and loss of primary flow transients.

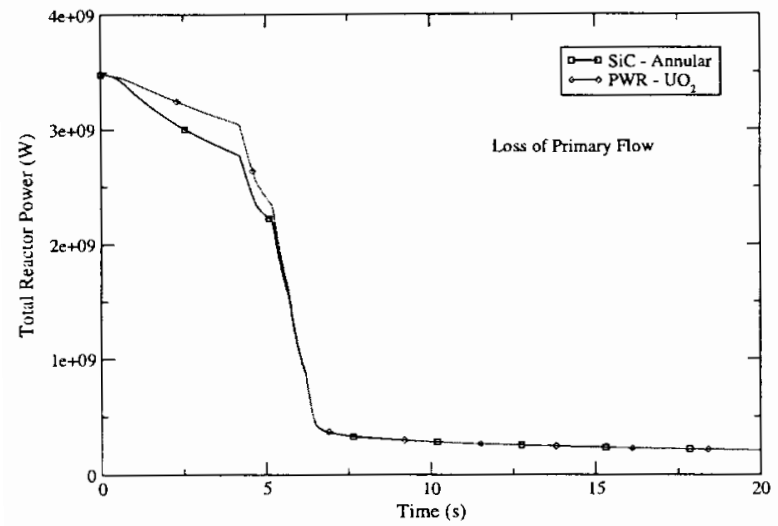

Fig. 5. Reactor power under loss of flow (LOF) transient.

rise. The negative moderator temperature coefficient then added negative reactivity to the core. This was reflected in a downward drift in core power before the reactor trip shown in Fig. 5. It

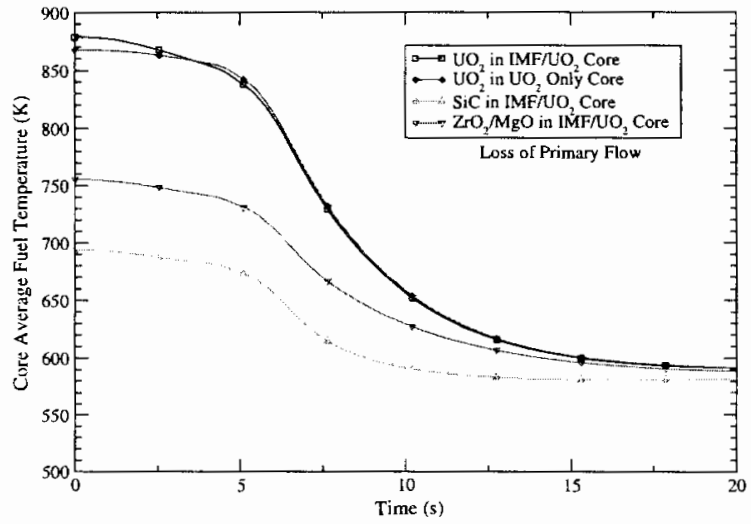

Fig. 6. Core average fuel temperature under loss of flow (LOF). is also of interest to note the responses of the fuel temperature for different fuel compositions. In general a fuel with higher thermal conductivity will have a lower fuel temperature as shown in Fig. 6 indicative of its ability to transfer heat to the clad/coolant boundary.

\section{Conclusions}

The results of the neutronic performance analysis show that there is no significant difference in the system criticality due to the matrix materials considered $\left(\mathrm{ZrO}_{2}, \mathrm{SiC}\right.$, or $\left.\mathrm{MgO}-\mathrm{ZrO}_{2}\right)$ assuming an 18month operating cycle.

- Other matrix materials such as $\mathrm{Zr}$-metal or $\mathrm{ZrO}_{2}-\mathrm{CaO}$ are potential candidates for additional consideration if the neutronic behavior is similar to that exhibited by the materials used in this study.

- The matrix material composition and fissile loading should be defined basing on thermo-hydraulic analysis (heat flux, DNBR, and fuel central-line temperature). The mechanical behavior of the fuel compositions under irradiation must be determined because the discharged accumulated burnup is very high and there is a high volumetric heat source in the fuel.

- The choice of matrix materials is affected by whether a once-through or recycle scenario is desired.

The results for the reactivity coefficients and control worths show that the soluble boron worth of IMF is lower (very similar to MOX case) than for UOX standard fuel. In addition, the IMF fuel 
has significant low Doppler coefficient. Using a burnable poison (BP) based on $\mathrm{Er}_{2} \mathrm{O}_{3}$ resonance absorber to significantly increase the Doppler coefficient will require compensating for the reduction in criticality with increased fissile loadings which may adversely affect other coefficients. Mixed UOX/IMF cores may be required to ensure that the reactor remains within its operational and safety envelope. Full three-dimensional simulations of mixed cores must be performed to confirm these results. Initial transient analysis shows that $\mathrm{ZrO}_{2}$ IMF fuel has higher peak clad temperature than UOX and SiC IMF fuel. The MgO- $\mathrm{ZrO}_{2}$ thermal conductivity can be adjusted by varying the $\mathrm{MgO} /$ $\mathrm{ZrO}_{2}$ ratio and measurements indicate that the achievable thermal conductivity is higher than the $5 \mathrm{~W} \mathrm{~m}^{-1} \mathrm{~K}^{-1}$ used in the calculations for this study. Initial analysis indicates that a $50 / 50 \mathrm{wt} \%$ mixture of $\mathrm{MgO}-\mathrm{ZrO}_{2}$ results in peak clad temperatures similar to UOX.

\section{Acknowledgements}

The authors thank Dr L. Cheng and Dr G. Raitses who performed the safety analyses presented in this paper.

Work supported by the US Department of Energy, Office of Nuclear Energy, Science, and Technology (NE), under DOE-NE Idaho Operations Office Contract DE-AC07-05ID14517.

\section{References}

[1] C. Degueldre, T. Yamashita, J. Nucl. Mater. 319 (2003) 1.

[2] G.S. Chang, J.M. Ryskamp, Nucl. Technol. 129 (2000) 326.

[3] J.S. Herring, P.E. MacDonald, K.D. Weaver, Nucl. Technol. 147 (2004).

[4] S. Eaton, C. Beard, K. Ramsey, J. Buksa, K. Chidester, Nucl. Sci. Eng. $136(2000) 151$.

[5] R.P.C. Schram, K. Bakker, H. Hein, J.G. Boshoven, R.R. van der Laan, C.M. Sciolla, T. Yamashita, Ch. Hellwig, F. Ingold, R. Conrad, S. Casalta, Progr. Nucl. Energy 38 (2001) 259.

[6] G. Ledergerber, C. Degueldre, P. Heimgartner, M.A. Pouchon, U. Kasemeyer, Progr. Nucl. Energy 38 (2001) 301.

[7] C. Hellwig, U. Kasemeyer, G. Ledergerber, B. Lee, Y.-W. Lee, R. Chawla, Ann. Nucl. Energy 30 (2003) 287.

[8] P.G. Medvedev, S.M. Frank, T.P.O. Holleran, M.K. Meyer, J. Nucl. Mater. 342 (2005) 48.

[9] P. Medvedev, Development of Dual Phase Magnesia-Zirconia Ceramics for Light Water Reactor Inert Matrix Fuel, PhD thesis, Texas A\&M University, December 2004.

[10] J. Porta, M. Asou, Progr. Nucl. Energy 38 (2001) 347.

[11] M. Todosow, G. Raitses, L.-Y. Cheng, J. Jo, A. Galperin, Initial Report on Safety and Licensing Issues Associated with the use of Inert Matrix Fuels in Light-Water Reactors (LWRs), Brookhaven National Laboratory Report, BNLAFCI-2004-002, November 2004.

[12] J.M. Paratte, K. Foskolos, P. Grimm, C. Maeder, The PSI Code System ELCOS for LWR Core Analysis, Paul Scherrer Institute, Villigen PSI, February 1996.

[13] COBRA-EN: Code System for Thermal-Hydraulic Transient Analysis of Light Water Reactor Fuel Assemblies and Cores, PSR-507, RSICC, ORNL, May 2001.

[14] RELAP5-3D Code Manual Volume 1: Code Structure, System Models and Solution Methods, INEEL-EXT-9800834, Revision 2.2, October 2003. 